\title{
RATIONAL CHOICE OF THERAPY IN PRIMARY OPEN ANGLE GLAUCOMA
}

\author{
JEFFREY L. JAY \\ Glasgow
}

The boundaries between ocular hypertension, primary open angle glaucoma and low tension glaucoma are indistinct but for the purpose of this paper, established primary open angle glaucoma will be defined as the stage of the disease with identified intraocular pressure above $21 \mathrm{mmHg}$, together with characteristic forms of visual field loss significantly beyond that expected for the age of the patient. The earlier phase of the disease in which there is pressure related loss of optic nerve axons but no loss of visual field will be left in the category of ocular hypertension but if an eye is suspected to be in this 'Quigley gap' it is usually treated as if it had primary open angle glaucoma. Evidence for this phase of the disease may be obtained from the appearance of the optic disc or analysis of the retinal nerve fibre layer, especially if sequential measurements show progressive loss. There are also several innovative psychophysical and electro-physiological tests competing for the ability to predict the visual field damage but in most cases evidence is not yet secure enough to give them a reliable place in routine clinical management decisions.

For primary open angle glaucoma with established visual field loss there is accumulating evidence from clinical trials ${ }^{1-5}$ on which to base choice of therapy. Informed decisions can now be made as to which of the three forms of therapy; medicines, argon laser trabeculoplasty or trabeculectomy, are appropriate to different stages of the disease depending on the level of intraocular pressure and severity of field loss. The patient's life expectancy ${ }^{3}$ and the likelihood of satisfactory compliance with treatment must also be considered..$^{6-8}$.

\section{CHOICE OF FIRST THERAPY}

The Glasgow trial of early trabeculectomy versus conventional management of medical therapy followed by trabeculectomy for cases which were not controlled medically ${ }^{3,4}$ has provided useful information. We studied eyes with untreated intraocular pressure over $25 \mathrm{mmHg}$

Correspondence to: Dr. J. L. Jay, Tennent Institute of Ophthalmology, The Western Infirmary, 38 Church Street, Glasgow G11 6NT. and all stages of visual field loss from mild relative scotomas to absolute loss of field within $5^{\circ}$ of fixation in all quadrants. Surgery has provided lower intraocular pressure than medical therapy and the groups were equivalent for visual acuity and rate of cataract formation. In the more severely affected eyes (intraocular pressure $>30 \mathrm{mmHg}$ before treatment and absolute scotomas even of small area) medical therapy failed to control approximately $70 \%$ of eyes at three years and so we now choose trabeculectomy as the primary form of therapy for eyes with this degree of damage. Sudden loss of the last central island of visual field after operation did not occur in this trial. It has been described ${ }^{9}$ but has not been experienced by all authors ${ }^{10}$ and others describe it as a rare event. ${ }^{11}$ Kolker $^{12}$ found the incidence to be similar to that occurring in medically treated cases with equivalent severity of field loss. It should therefore not be used as an excuse to avoid surgery. However, in eyes with only a small terminal island of central field, the risk of early postoperative rise in intraocular pressure should be reduced by giving carbonic anhydrase inhibitors or beta-blocker eye drops at the end of the operation.

Only about $30 \%$ of eyes with milder disease (intraocular pressure $<30 \mathrm{mmHg}$ and relative scotomas) required operation at three years of follow-up ${ }^{3,4}$ and, therefore, it still seems appropriate to attempt medical control in these milder cases. This must be closely monitored as apparently satisfactory lowering of pressure by medical means does not ensure prevention of visual field deterioration. Figure 1 shows the indications for trabeculectomy in those eyes which were not controlled medically. Eyes which were identified as having unsatisfactory reduction of pressure by medical therapy were rapidly identified and submitted to operation at a median time of four months after diagnosis. There was, as might be expected, significantly greater delay before operating on those where the indication included progressive loss of field, whether or not accompanied by unsatisfactory intraocular pressure. Median time to operation was 11 months for eyes where the indication was high pressure and field loss, and 17 


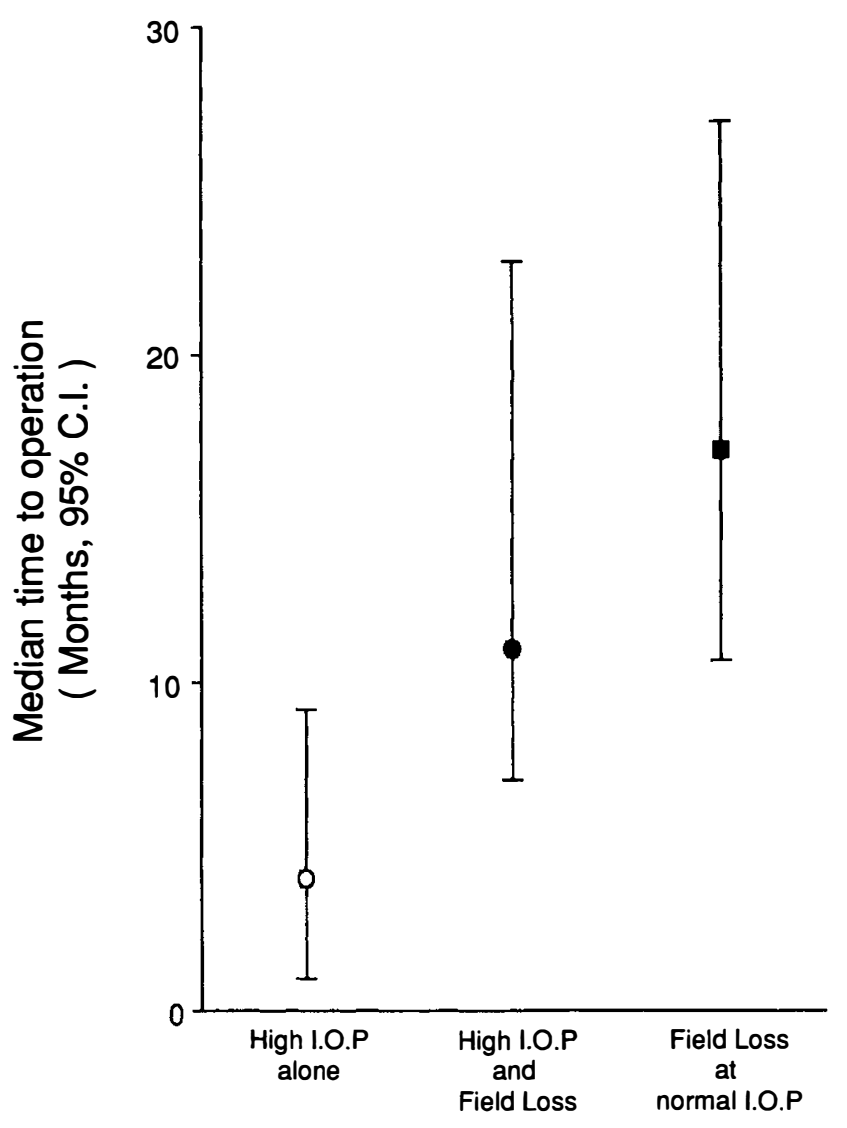

Indication for operation

Fig. 1. Indications for trabeculectomy following failure of medical treatment. The time from diagnosis to operation was significantly shorter where the indication was high intraocular pressure alone than where deterioration of visual field had been identified. See text for statistical analysis.

months for field loss with apparently normal pressure. The Mann-Whitney test indicated no significant difference in delay to operation between those where the indication was progressive field loss and high pressure compared with those with normal pressure $(\mathrm{p}=0.35)$, but there was a significant difference between those where the indication was high intraocular pressure alone compared with field loss at normal pressure $(\mathrm{p}=0.01)$ and field loss with high pressure $(\mathrm{p}=0.03)$.

The group treated by early surgery suffered less visual field loss than the one in which medical control was attempted and the difference arose entirely in the period of attempted medical control which had delayed trabeculectomy.

Visual field tests throughout the duration of the Glasgow trial were performed manually with the Tubingen Occulus perimeter and, for the sake of continuity, remained so after automated perimetry became available. Field changes were categorised in five stages: Stage 1. Mild relative scotomas to a 1.0/10asb target (Goldmann equivalent I-2e) in a glaucomatous pattern. Stage 2. Absolute scotomas, 1.0/00asb (Goldmann equivalent I-4e) in a glaucomatous pattern but greater than $10^{\circ}$ from fixation. Stage 3 . Scotomas between $5^{\circ}$ and $10^{\circ}$ of fixation in one to four quadrants with the same target. Stage 4 . Within $5^{\circ}$ fixation in one to four quadrants; and Stage 5. Within $5^{\circ}$ of fixation in all quadrants, target as for Stages 2 and 3. For analysis, deterioration or improvement in field sufficient to move from one stage to another was used. This simple method measures only large steps in visual field change, each of clear clinical significance in the course of progression of the disease.

\section{EFFECT OF DELAY BEFORE OPERATION (a) On Visual Field Loss}

The detrimental effect of this delay was emphasised by the finding that those with the mildest visual field defects at diagnosis showed the most severe progressive loss and this was related to a more prolonged attempt at medical control (mean, 23 months) in these eyes compared with eyes more severely damaged at the time of diagnosis (mean, 11 months). It seemed the surgeons' perception that the eyes with less damage were at less risk of field loss led them to a more prolonged attempt at medical control, with detrimental result.

\section{(b) On Surgical Success}

Delays of this order are certainly a hazard for visual field survival but they do not seem to jeopardise the eventual success of the operation. The group mean pressure after trabeculectomy, whether as a primary procedure or for failed medical control, was identical at $15 \mathrm{mmHg}$. Fig. 2 shows in more detail the similar pattern of success of primary trabeculectomy compared with delayed trabeculectomy. Various criteria of success are set out but more than $90 \%$ of eyes achieved worthwhile pressure reduction. Figures for success defined by various indications for supplementary medical therapy are shown. As can be seen, medical therapy was often added when there had been satisfactory pressure reduction after operation.

It therefore appears that two or three years of medical therapy does not make the operation less successful. More prolonged medication may, however, have a detrimental effect. In a retrospective comparison, Lavin et al.$^{13}$ found trabeculectomy less successful after a mean time of 77 months of medical therapy compared with primary trabeculectomy. Prolonged medication may carry a risk of a pemphigoid reaction in the conjunctiva ${ }^{14}$ and increased amounts of inflammatory cells have been identified in conjunctival biopsies after prolonged medical therapy. ${ }^{15}$

Eyes with encapsulated filtering blebs have been reported as being more commonly associated with prolonged beta-blocker therapy ${ }^{16}$ and a rise in pressure with topical steroids in the post-operative period was more common in eyes which had prior medical therapy than those without. ${ }^{17}$ These two causes of early postoperative pressure rise may be the same.

\section{CHOICE OF MEDICAL THERAPY}

A brief trial of closely supervised medical therapy is clearly the appropriate first line of treatment in the less severe cases. Fig. 3 shows the number of different prep- 


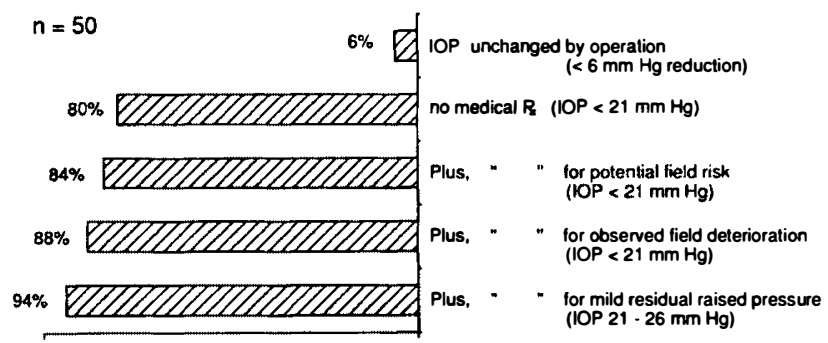

Results of Primary Trabeculectomy

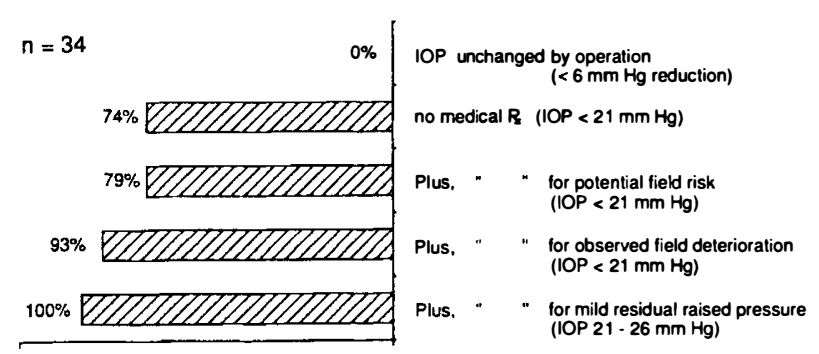

Results of delayed Trabeculectomy

Fig. 2. Success of primary trabeculectomy compared with delayed operation where the average delay while medical control was attempted was less than two years (see Fig. 1). Different criteria for success are given. The results are similar.

arations used in the trial of conventional management group ${ }^{3}$ with separate data for those eventually requiring operation at a mean follow-up of 4.7 years. It can be seen that satisfactory medical control (shaded bars) was most often achieved with one or two drugs and, as might be expected, addition of further agents was less likely to be useful. Fig. 4 shows the frequency of use of each main group of drugs. Pilocarpine and timolol were the most popular. The type of drug used was not related to the probability of successful medical control and the frequency of drug withdrawal because of side effects varied; $44 \%$ for

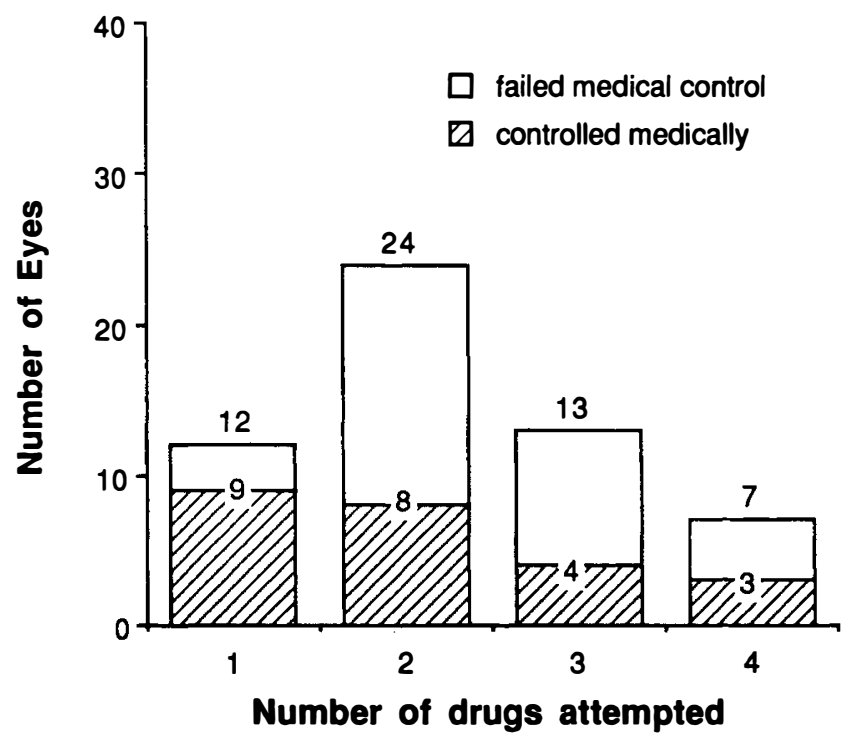

Fig. 3. The number of different drugs tried in the conventional management group. ${ }^{3}$ Where there was a need to try more than one drug the probability of successful medical control diminished. carbonic anhydrase inhibitors, $18 \%$ for adrenergic agents, $2 \%$ for timolol and $7 \%$ for pilocarpine. The low figure for timolol probably indicates that the drug was not tried in the presence of cardio-respiratory contraindications, whereas there are few contraindications for the other drugs which would prevent at least a trial of their use. Four fatalities linked to beta-blocker eye drops were reported to the Committee of Safety of Medicines in the United Kingdom up to June $1990 .{ }^{18}$ Therefore, scrupulous care must be taken to avoid this category of drug where there is the slightest suspicion of an increased risk of bronchospasm, bradycardia or cardiac failure. Even after initial satisfactory medical control, many eyes show gradually increasing pressure in later years while on the same therapy. This is more likely to be caused by progression of the disease than by treatment wearing off. ${ }^{19}$

\section{THE CHANGING ROLE OF ARGON LASER TRABECULOPLASTY}

This form of treatment was introduced in $1979^{20}$ and at first used in the hope of avoiding drainage surgery in eyes uncontrolled on maximum medical therapy, but it was found to delay rather than avoid surgical operation ${ }^{21}$ and is not without risk. ${ }^{22}$ Its effectiveness depends on the experience and skill of the operator ${ }^{23}$ and in this it differs from trabeculectomy, the success of which does not depend on the experience of the surgeon. ${ }^{24,25}$ Argon laser trabeculoplasty is more likely to be successful in eyes with pseudoexfoliation, pigmented meshwork or lower pretreatment pressure levels, especially in patients over 60 years of age. ${ }^{26}$ Initially successful in about $75 \%$ of cases, depending on how success is defined, it becomes gradually less effective with time. Between $5 \%$ and $10 \%$ of eyes escape from control each year of follow-up ${ }^{27-31}$ and the effect of treatment is less sustained in black patients. ${ }^{32}$

Current interest in argon laser trabeculoplasty has moved from its use as a means of avoiding surgery in cases escaping from medical control, to direct comparison with medical therapy as a first line of treatment in newly diagnosed cases. If effective, it should remove the worry about

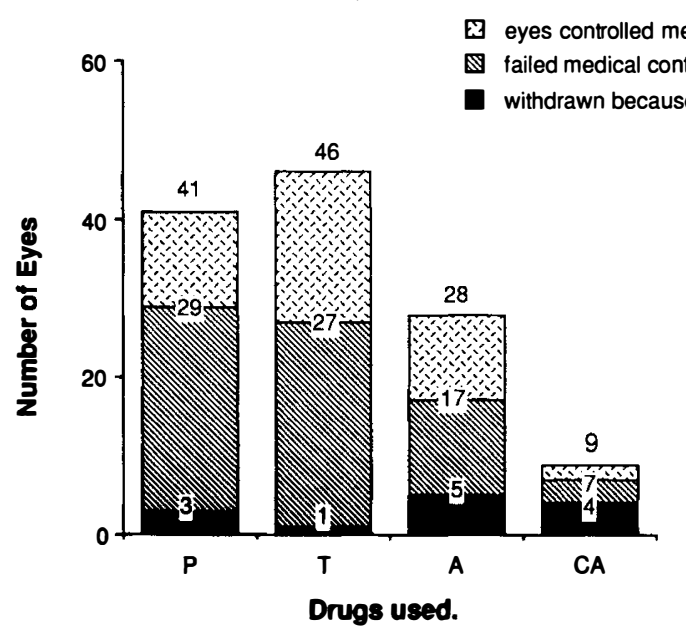

Fig. 4. Frequency of use and of withdrawal because of side effects for each drug. $(P=$ pilocarpine, $T=$ timolol, $\boldsymbol{A}=$ adrenergic agents, $\boldsymbol{C A}=$ carbonic anhydrase inhibitors). 
compliance with medical therapy but the high rate of escape from control will require close supervision after laser treatment. Initial results for two randomised prospective studies comparing primary argon laser trabeculoplasty with primary medical therapy have shown either no difference in outcome or only marginal advantage for laser therapy ${ }^{33,34}$ This is disappointing as even if the only benefit of laser therapy had been the avoidance of poor patient compliance, a greater difference might have been expected. Therefore, it seems there is little to choose between primary laser therapy and primary medical therapy.

\section{THE RATE OF VISUAL FIELD DECAY IN PRIMARY OPEN ANGLE GLAUCOMA}

The importance of achieving control in the first few months of treatment has been identified in the results of the Glasgow trial and from the rate of decay of group mean visual field in the first four years of treatment we can extrapolate to obtain slopes of visual field decay during different phases of treatment. Such extrapolation is unlikely to be an accurate description of individual cases. There will probably be a variable rate of field loss for different individuals and even for the same individual, depending on changes in treatment and level of intraocular pressure. It will, however, serve to emphasise the hazard of unsatisfactory treatment and quantify the benefit to be gained from optimum treatment.

Figure 5 shows three slopes of the derived time it might take to progress from the earliest detectable relative field defects of glaucoma to absolute loss of field within $5^{\circ}$ of fixation, assuming that this is a linear function. Slope (a) is derived from the group mean rate of decay of visual field in the first year of conventional treatment. It includes patients later identified as uncontrolled medically and is therefore a measure of the decay which might be expected with less than perfect treatment. The disease may progress to blindness in about ten years under these conditions. Slope (b) indicates the overall decay for the first four years of conventional management, allowing inclusion of improved control achieved by surgery for those identified as being uncontrolled medically. This lengthens the progress of the disease to 19 years. Slope (c) takes 38 years to progress to blindness and represents stable optimum treat-

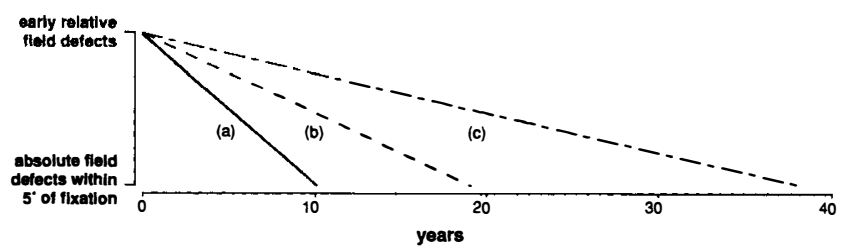

Fig. 5. Extrapolation of rate of visual field decay at different stages of conventional treatment. The slopes are estimates of the time from earliest diagnostic field defects to end stage disease. Derived (a) from group average rate of change during first year of treatment, (b) from average of first four years, (c) from end of year 2 onwards representing optimum stable therapy excluding the early period of identifying and operating on eyes not satisfactory on medical treatment. Slope (c) is similar to that derived for first and subsequent years in the early trabeculectomy group. ment with the unstable period of the first two years removed. It is during these two years that most operations were performed for poor medical control. This optimum slope is similar to the slope of field decay for the first four years in the group treated by trabeculectomy at diagnosis. There seems much to be gained by choosing the best treatment. In his Lang lecture, Redmond Smith calculated that there was a field decay of about $3 \%$ per annum for treated primary open angle glaucoma. ${ }^{2}$ Again, assuming a linear decay with time, it would take about 33 years to progress to blindness, a figure almost identical with data in Fig. 5. There were trends in his data which indicated a longer period for eyes treated by primary surgery (66 years). The most rapid projected field decay was for eyes which required operation for failed medical control ( 25 years).

It is known that visual fields in glaucoma patients may continue to deteriorate in some cases after apparently successful lowering of intraocular pressure by trabeculectomy. ${ }^{35}$ These eyes may have more labile intraocular pressure than those which maintain stable visual fields. ${ }^{36}$ This explains the continued loss in average visual field performance even with optimum treatment but, as has been shown, this is a much slower loss than may occur with less satisfactory treatment.

\section{CONCLUSION}

Enough critical information is now available on the effects and side effects of the various forms of treatment that a rational choice is possible. Nihilism should be discarded. We recommend trabeculectomy soon after diagnosis without a trial of medical therapy in eyes presenting with pressure over $30 \mathrm{mmHg}$ and with absoloute areas of field loss, even if of small area. Less advanced cases may be given a brief trial of either medical therapy or argon laser trabeculoplasty but should be offered trabeculectomy if the intraocular pressure is not satisfactory within a few weeks. If the pressure does appear satisfactory within this period, then close monitoring of visual field should identify those who still deteriorate. Trabeculectomy is then offered without attempting to improve medical control.

\section{REFERENCES}

1. Smith RJH: Medical versus surgical therapy in glaucoma simplex. Br J Ophthalmol 1972, 56: 277-83.

2. Smith RJH: The enigma of primary open angle glaucoma. Trans Ophthalmol Soc UK 1986, 105: 618-33.

3. Jay JL and Murray SB: Early trabeculectomy versus conventional management in primary open angle glaucoma. $\mathrm{Br} J$ Ophthalmol 1988, 72: 881-9.

4. Jay JL and Allan D: The benefit of early trabeculectomy versus conventional management in primary open angle glaucoma relative to severity of disease. Eye 1989, 3: 528-35.

5. Migdal C and Hitchings R: Control of chronic simple glaucoma with primary medical, surgical and laser treatment., Trans Ophthalmol Soc UK 1986, 105: 653-6.

6. Kass MA, Meltzer DW, Gordon IM et al.: Compliance with topical pilocarpine treatment. Am J Ophthalmol 1986, 101: 515-23.

7. Kass MA, Gordon M, Morley RE et al.: Compliance with topical timolol treatment. Am J Ophthalmol 1987, 103: 188-93. 
8. Kass MA, Gordon M, Meltzer DW: Can ophthalmologists correctly identify patients defaulting from pilocarpine therapy? Am J Ophthalmol 1986, 101: 524-30.

9. Lichter PR and Ravin JG: Risks of sudden visual loss after glaucoma surgery. Am J Ophthalmol 1974, 78: 1009-13.

10. Honrubia FM, Abad MP, Gomez ML et al.: Surgery for preterminal glaucoma with residual central 'islet'. Arch Soc Esp Ophthalmol 1980, 40: 1228-32.

11. Aggarwal SP and Hendeles S: Risk of sudden visual loss following trabeculectomy in advanced primary open angle glaucoma. Br J Ophthalmol 1986, 70: 97-9.

12. Kolker AE: Visual prognosis in advanced glaucoma. In: Cairns J (ed) Glaucoma. Grune \& Stratton, London, 1986, pp 647-660.

13. Lavin MJ, Wormald RPL, Migdal CS, Hitchings RA: The influence of prior therapy on the success of trabeculectomy. Arch Ophthalmol 1990, 108: 1543-8.

14. Tauber J, Melamed S, Foster CD: Glaucoma in patients with ocular cicatricial pemphigoid. Ophthalmology 1989, 96: 33-7.

15. Sherwood MB, Grierson I, Miller L et al.: Long term morphologic effects of anti glaucoma drugs on the conjunctiva and Tenon's capsule in glaucomatous patients. Ophthalmology 1989, 96: 327-35.

16. Richter CU, Shingleton BJ, Bellows AR et al.: The development of encapsulated filtering blebs. Ophthalmology 1988, 95: $1163-8$.

17. Thomas R and Jay JL: Raised intraocular pressure with topical steroids after trabeculectomy. Graefe's Arch Clin Exp Ophthalmol 1988, 226: 337-40.

18. Committee on Safety of Medicines 1990 Personal Communication.

19. Chauhan BC, Drance SM, Douglas GR: The time course of intraocular pressure in timolol treated and untreated glaucoma suspects. Am J Ophthalmol 1989, 107: 471-5.

20. Wise JB and Witter SL: Argon laser therapy for open angle glaucoma: a pilot study. Arch Ophthalmol 1979, 97: 319-22.

21. Gilbert CM, Brown RH, Lynch MG: The effect of argon laser trabeculoplasty on the rate of filtering surgery. Ophthalmology 1986, 93: 362-5.

22. Hoskins HF Jr, Hetherington J Jr, Minkler DS et al.: Com- plications of laser trabeculoplasty. Ophthalmol 1983, 40: 796-9.

23. Khan KA, Lederer CM Jr, Willoughby L: Argon laser trabeculoplasty in a residency program. Ophthalmic Surg 1986, 17: 343-50.

24. Murray SB and Jay JL: Trabeculectomy: its role in the management of glaucoma. Trans Ophthalmol Soc UK 1979, 99: 492-4.

25. Morrell AJ, Searle AET, O'Neil EC: Trabeculectomy as an introduction to intraocular surgery in an ophthalmic training program. Ophthalmic Surg 1989, 20: 557-60.

26. Ticho U and Nescher R: Laser trabeculoplasty in glaucoma: ten-year evaluation. Arch Ophthalmol 1989, 107: 844-6.

27. Lehmann FA and Faggioni R: Two years experience with argon laser trabeculoplasty. Klin Monatsbl Augenheilkd 1986, 188: 519-22.

28. Moulin F, Haut J, Abi Rached J: Late failures of trabeculoplasty. Int Ophthalmol 1987, 10: 61-6.

29. Wise JB: Ten-year results of laser trabeculoplasty. Eye 1987, 1: 45-50.

30. Fink AI, Jordan AJ, Lao PN et al.: Therapeutic limitation of argon laser trabeculoplasty. $\mathrm{Br} J$ Ophthalmol 1988, 72: 263-9.

31. Lund OE and Zink $\mathrm{H}$ : Long term results of argon laser trabeculoplasty. Klin Monatsbl Augenheilkd 1988, 193: 572-8.

32. Schwartz AL, Love DC, Schwartz MA: Long term follow-up of argon laser trabeculoplasty for uncontrolled open angle glaucoma. Arch Ophthalmol 1985, 103: 1482-4.

33. Tuulonen A, Koponen J, Alanko HI et al.: Laser trabeculoplasty versus medication treatment as primary therapy for glaucoma. Acta Ophthalmol 1989, 67: 275-80.

34. The glaucoma laser trial research group: 2 . Results of argon laser trabeculoplasty versus topical medicines. Ophthalmology 1990, 97: 1403-13.

35. Kidd MN, O'Connor M: Progression of field loss after trabeculectomy: a five-year folow-up. Br J Ophthalmol 1985, 69: 827-31.

36. Werner EB, Drance SM, Schulzer M: Trabeculectomy and the progression of glaucomatous visual field loss. Arch Ophthalmol 95: 1374-1377. 